\title{
Headache characteristics in subarachnoid haemorrhage and benign thunderclap headache
}

\author{
F H H Linn, G J E Rinkel, A Algra, J van Gijn
}

\begin{abstract}
One third of patients with aneurysmal subarachnoid haemorrhage (ASAH) present with headache only. A prompt diagnosis is crucial, but these patients must be distinguished from patients with non-haemorrhagic benign thunderclap headache (BTH). The headache characteristics and associated features at onset in subarachnoid haemorrhage and benign thunderclap headache were studied to delineate the range of early features in these conditions. In this prospective study, one of two observers interviewed 102 patients with acute severe headache by means of a standard questionnaire. The patients were alert on admission and had no focal deficits. ASAH was subsequently diagnosed in 42 patients, non-aneurysmal perimesencephalic haemorrhage (PMH) in 23 patients, and $B T H$ in 37 patients. Headache developed almost instantaneously in $50 \%$ of patients with ASAH, 35\% of patients with $\mathrm{PMH}$, and $68 \%$ of patients with BTH and within 1 to 5 minutes in $19 \%, 35 \%$, and $19 \%$, respectively. Loss of consciousness was reported in $26 \%$ of patients with ASAH, 4\% of patients with PMH and $16 \%$ of patients with BTH, and transient focal symptoms in $33 \%, 9 \%$, and $22 \%$ respectively. Seizures and double vision had occurred only in ASAH. Vomiting and physical exertion preceding the onset of headache were more frequent in patients with ASAH (69\% and $50 \%)$ and those with PMH (83\% and 39\%) than in those with BTH (43\% and $22 \%)$. Headache developed almost instantaneously in only half the patients with aneurysmal rupture and in two thirds of patients with benign thunderclap headache. In patients with acute severe headache, female sex, the presence of seizures, a history of loss of consciousness or focal symptoms, vomiting, or exertion increases the probability of ASAH, but these characteristics are of limited value in distinguishing ASAH from BTH. Aneurysmal rupture should be considered even if focal signs are absent and the headache starts within minutes. (F Neurol Neurosurg Psychiatry 1998;65:791-793)
\end{abstract}

Keywords: aneurysm; subarachnoid haemorrhage; headache
Aneurysmal subarachnoid haemorrhage (ASAH) is a devastating disorder; about $75 \%$ of patients die or are left severely disabled from the haemorrhage. ${ }^{1}$ The hallmark of ASAH is onset of almost instantaneous headache; in two thirds of patients this headache is accompanied by loss of consciousness or focal deficits, ${ }^{2}$ and in these patients an ASAH is easily recognised. However, in up to one third of patients with ASAH symptoms or signs consist of headache alone. ${ }^{3}$ It is especially important to recognise the patients who are alert and without deficits, because they may benefit most from early clipping of the aneurysm. ${ }^{4}$ Patients without loss of consciousness or focal deficits may also have either of two other conditions, both with good prognosis: non-haemorrhagic thunderclap headache, ${ }^{5}$ or perimesencephalic haemorrhage $(\mathrm{PMH})$, a benign, non-aneurysmal variety occurring in $10 \%$ of patients with subarachnoid haemorrhage (SAH) ${ }^{6}$

To delineate the range of symptoms at onset of ASAH and to investigate which features occurring at onset might differentiate between aneurysmal rupture, $\mathrm{PMH}$, and benign thunderclap headache (BTH), we interviewed a consecutive series of patients with acute severe headache who were fully alert on admission and had no obvious neurological abnormalities.

\section{Methods}

Between January 1992 and October 1994 we studied 102 adult patients referred by general practitioners to the emergency room of the Utrecht University Hospital with a sudden onset of headache suggestive of ASAH. Further inclusion criteria were a normal level of consciousness and absence of focal deficits on admission. Brain CT was performed in all patients, and if it showed no blood, lumbar puncture was done at least 12 hours after the onset of headache. ${ }^{7}$ Patients in whom CT or other investigations showed a definite cause other than SAH were excluded from the outset.

Within 24 hours of admission a detailed history was obtained by means of a standard questionnaire, by one of two observers (FHHL, GJER). We recorded the following characteristics of headache: rapidity of onset, feelings at onset as if something had "burst", previous headaches, a transient loss or clouding of consciousness, seizures, transient focal symptoms, nausea and vomiting, and 
Patient and headache characteristics of 102 patients with sudden severe headache

\begin{tabular}{|c|c|c|c|c|c|}
\hline & $A S A H$ & $P M H$ & $B T H$ & $\begin{array}{l}R R(95 \% C I) \\
A S A H v B T H\end{array}$ & $\begin{array}{l}\text { RR ( } 95 \% \text { CI) ASAH } \\
\text { and PMH v BTH }\end{array}$ \\
\hline No & 42 & 23 & 37 & & \\
\hline Female sex & $24(57 \%)$ & $6(26 \%)$ & $13(35 \%)$ & $1.6(1.0-2.7)$ & $1.3(0.8-2.2)$ \\
\hline Age (y (mean (SD)) & $49(14)$ & $56(11)$ & $36(13)$ & & \\
\hline $\begin{array}{l}\text { Exertion/Valsalva-like manoeuvre at } \\
\text { onset }\end{array}$ & $21(50 \%)$ & $9(39 \%)$ & $8(22 \%)$ & $2.3(1.2-4.6)$ & $2.1(1.1-4.2)$ \\
\hline $\begin{array}{l}\text { Feeling of a "burst" } \\
\text { Onset of headache:* }\end{array}$ & $5(12 \%)$ & $1(4 \%)$ & $5(14 \%)$ & - & - \\
\hline Almost instantaneous & $21(50 \%)$ & $8(35 \%)$ & $25(68 \%)$ & $0.7(0.5-1.1)$ & $0.7(0.5-0.9)$ \\
\hline $2-60 \mathrm{~s}$ & $10(24 \%)$ & $6(26 \%)$ & $2(5 \%)$ & - & - \\
\hline $\begin{array}{l}1-5 \mathrm{~min} \\
>5 \mathrm{~min}\end{array}$ & $8(19 \%)$ & $\begin{array}{l}8(35 \%) \\
1(4 \%)\end{array}$ & $\begin{array}{l}7(19 \%) \\
1(3 \%)\end{array}$ & $1.0(0.4-2.5)$ & $1.3(0.6-2.9)$ \\
\hline $\begin{array}{l}\text { Severity score of present headache } \\
(0-10 ; \text { median (range }) t\end{array}$ & $10(7-10)$ & $10(7-10)$ & $9(7-10)$ & & \\
\hline $\begin{array}{l}\text { Number of patients with frequent } \\
\text { previous headaches }\end{array}$ & $16(38 \%)$ & $8(35 \%)$ & $21(57 \%)$ & $0.7(0.4-1.1)$ & $0.7(0.4-1.1)$ \\
\hline $\begin{array}{l}\text { Severity score frequent previous } \\
\text { headache }(0-10 ; \text { median (range) })\end{array}$ & $6(4-10)$ & $5(1-9)$ & $4(1-7)$ & & \\
\hline Nausea & $32(76 \%)$ & $19(83 \%)$ & $28(76 \%)$ & $1.0(0.8-1.3)$ & $1.0(0.8-1.3)$ \\
\hline Vomiting & $29(69 \%)$ & $19(83 \%)$ & $16(43 \%)$ & $1.6(1.1-2.4)$ & $1.7(1.1-2.5)$ \\
\hline $\begin{array}{l}\text { Preceding headache resembling the } \\
\text { present headache }\end{array}$ & $8(19 \%)$ & $1(4 \%)$ & $5(14 \%)$ & - & - \\
\hline Seizure & $3(7 \%)$ & - & - & & \\
\hline $\begin{array}{l}\text { Transient loss or clouding of } \\
\text { consciousness } \ddagger\end{array}$ & $11(26 \%)$ & $1(4 \%)$ & $6(16 \%)$ & $1.6(0.7-3.9)$ & $1.1(0.5-2.8)$ \\
\hline Transient focal symptoms $\ddagger$ & $14(33 \%)$ & $2(9 \%)$ & $8(22 \%)$ & $1.5(0.7-3.3)$ & $1.1(0.5-2.4)$ \\
\hline
\end{tabular}

ASAH=aneurysmal subarachnoid haemorrhage; $\mathrm{PMH}=$ perimesencephalic haemorrhage; $\mathrm{BTH}=$ benign thunderclap headache; $\mathrm{RR}=$ relative risk; $95 \% \mathrm{CI}=$ confidence interval.

${ }^{\star}$ Onset of headache occurred in one patient with ASAH and two patients with BTH during waking up; two patients with ASAH could not describe onset of headache.

†37 patients $(88 \%)$ with SAH and 34 patients $(92 \%)$ with BTH could give a severity score for the present headache.

$¥ 11$ patients had more than one symptom.

- For several characteristics no relative risks could be calculated because of small numbers.

precipitating circumstances such as exertion or activities involving a Valsalva-like manoeuvre. We asked patients to grade the severity of their headache on a scale from $0-10(0=$ no pain; $10=$ the worst pain ever). If the patients had had frequent previous headaches (defined as at least once every 3 months), we also asked them to grade the severity of this former headache compared with the present one. Amnesia, drowsiness or confusion, as reported by the patient, were classified as clouding of consciousness. We categorised transient focal symptoms at onset, as reported by the patients, into double vision, speech arrest, sensory phenomena or weakness in the face or limbs (unilateral or bilateral), and difficulties with walking.

The diagnosis of ASAH, PMH, and BTH were as described previously. ${ }^{5-7}$ The investigations eventually established the diagnosis of ASAH in 42 patients (41\%), PMH in 23 patients $(23 \%)$ and $\mathrm{BTH}$ in 37 patients $(36 \%)$.

\section{Data analysis}

We compared proportions between groups by means of relative risks (RRs) or mean differences, as appropriate, with their corresponding $95 \%$ confidence intervals (95\% CIs). We compared the headache characteristics for the patients with ASAH versus BTH, and also for ASAH together with PMH versus BTH.

\section{Results}

In only half the patients with ASAH did the headache develop almost instantaneously; in almost a fifth the headache came on gradually, as in minutes rather than in seconds (table). All patients with frequent previous headaches rated the severity of the present headache higher than their usual type of headache.
Transient loss of consciousness (range 1-10 minutes), was reported by $26 \%$ of patients with ASAH, $4 \%$ of patients with $\mathrm{PMH}$, and $16 \%$ of patients with BTH. Of the transient focal symptoms, seizures and double vision were reported exclusively by patients with ASAH (by $7 \%$ and $5 \%$ of patients respectively). All other symptoms (sensory symptoms, weakness, difficulties with walking, and speech arrest), occurred in all three groups.

In the entire group, the positive predictive value of onset of almost instantaneous headache was $0.39(21 / 54)$ for ASAH versus PMH and $\mathrm{BTH}$ and that of transient loss of consciousness was $0.61(11 / 18)$.

\section{Discussion}

We found that the onset of headache in ASAH was not instantaneous in half of the patients, and up to minutes in a fifth. This is by contrast with the notion that ASAH is characterised by excruciating headache starting almost instantaneously. ${ }^{8}$ Very rapid onset occurred even more often in patients with BTH: thus the speed of onset of headache in patients with acute severe headache cannot be used to distinguish ASAH from BTH. All patients rated the present headache as the worst pain ever. The sudden onset and the severity of the headache may have been decisive factors for general practitioners to refer patients to our hospital. Although the series, therefore, is biased towards patients with a sudden onset of headache, our findings convincingly show that a sudden onset, excruciating pain, and transient focal symptoms are all compatible with BTH.

We found that only two characteristics, seizures and double vision, occurred exclusively in patients with ASAH, but these 
characteristics are not helpful in distinguishing ASAH from BTH because of their low frequency. Other characteristics, such as female sex, vomiting, exertion, transient loss of consciousness, and focal symptoms, were found more often in patients with ASAH than in patients with BTH, but because of their relatively high frequency in the BTH group, these features cannot be used to distinguish ASAH from BTH, at least not in the group selected for this study. The predictive value of each clinical feature depends on the relative proportions of subarachnoid haemorrhage versus $\mathrm{BTH}$, and these clearly reflect referral patterns. In general practice, $25 \%$ of all patients with sudden, severe headache have subarachnoid haemorrhage, ${ }^{2}$ and in a consecutive series from our own hospital service this proportion was $68 \% .^{9}$

It is difficult to compare our results with other studies, because in some of these only patient records were reviewed, or $\mathrm{PMH}$ was not included as a separate entity. ${ }^{5}{ }^{10-12}$ Nevertheless, the frequency of transient loss of consciousness and focal signs in our SAH and PMH groups was similar to that in other studies. ${ }^{611}{ }^{12}$ The frequency of transient loss of consciousness and focal symptoms in our BTH group was higher than in other studies: two large series on BTH reported each only one patient with neurological disturbance; one with a dilated pupil without a known cause, ${ }^{5}$ and one with a collapse $^{10}$; and in our previous prospective study in general practice on acute severe headache, ${ }^{2}$ only $8 \%$ of patients with BTH had reported loss of consciousness or focal symptoms. One explanation for the higher frequency of these characteristics in the present study might be that we specifically enquired about transient focal symptoms, by contrast with one study in which only records of patients were reviewed. ${ }^{5}$ Secondly, in our study only two investigators interviewed the patients, with a standard questionnaire, by contrast with our previous study in which any of the participating general practitioners asked patients about neurological symptoms. ${ }^{2}$ Thirdly, the difference from the other studies may be a chance event because of the wide $95 \%$ CIs of our estimate of loss of consciousness $(6 \%-32 \%)$ and focal symptoms (10\%-38\%). A limitation of our study design is that the frequencies of patient and headache characteristics can be applied only to the subset of patients with acute severe headache caused by either subarachnoid haemorrhage or unspecified but innocuous factors (BTH), because we deliberately excluded other causes of acute headache.

In conclusion, our findings indicate that aneurysmal rupture may be suspected even if onset of headache is within minutes rather than in seconds and that other characteristics at onset of headache such as female sex, a history of loss of consciousness or focal symtoms, vomiting, and exertion cannot be used safely to distinguish subarachnoid haemorrhage from BTH. A thorough history of headache characteristics by a general practitioner or in the emergency room does not exclude the need for ancillary investigations (CT, and lumbar puncture if this is negative).

1 Hop JW, Rinkel GJE, Algra A, et al. Case fatality rates and functional outcome after subarachnoid hemorrhage: a systematic review. Stroke 1997;28:660-4.

2 Linn FHH, Wijdicks EFM, van der Graaf Y, Weerdesteynvan Vliet FAC, Bartelds AIM, van Gijn J. Prospective study of sentinel headache in aneurysmal subarachnoid haemorrhage. Lancet 1994;344:590-3.

3 Ferro JM, Lopes J, Melo TP, et al. Investigation into the causes of delayed diagnosis of subarachnoid hemorrhage. Cerebrovasc Dis 1991;1:160-164.

4 Kassell NF, Torner JC, Haley EC, et al. The international cooperative study on the timing of aneurysm surgery. Part 1: overall management results. F Neurosurg 1990;73:18-36.

5 Wijdicks EFM, Kerkhoff H, van Gijn J. Long-term follow-up of 71 patients with thunderclap headache mimicking subarachnoid hemorrhage. Lancet 1988;ii:68 70 .

6 Rinkel GJE, Wijdicks EFM, Vermeulen M, et al. The clinical course of perimesencephalic nonaneurysmal subarachnoid hemorrhage. Ann Neurol 1991;29:463-8.

noid hemorrhage. Ann Neurol 1991;29:463-8.
7 Vermeulen M, van Gijn J. The diagnosis of subarachnoid Vermeulen M, van Gijn J. The diagnosis of subarachnoid
haemorrhage. $\mathcal{F}$ Neurol Neurosurg Psychiatry 1990;53:36572.

8 Vermeulen M, Lindsay KW, van Gijn J. Cerebral aneurysms: development and rupture. In: Subarachnoid haemorrhage. London: Saunders, 1992:1-15.

9 van der Wee N, Rinkel GJE, Hasan D, et al. Detection of subarachnoid haemorrhage on early CT: is lumbar puncture still needed after a negative scan? $\mathcal{F}$ Neurol Neurosurg Psychiatry 1995;58:357-9.

10 Markus H. A prospective follow up of thunderclap headache mimicking subarachnoid haemorrhage. F Neurol Neurosurg mimicking subarachnoid ha.

11 Hauerberg J, Andersen BB, Eskesen V, et al. Importance of the recognition of a warning leak as a sign of a ruptured intracranial aneurysm. Acta Neurol Scand 1991;83:61-4.

12 Verweij RD, Wijdicks EFM, van Gijn J. Warning headache in aneurysmal subarachnoid hemorrhage. Arch Neurol 1988;45:1019-20. 